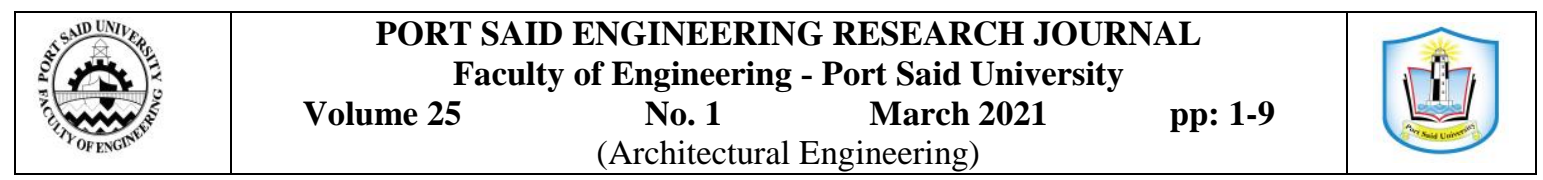

\title{
Bio-inspired Chameleon's Color Change in Building's Skin: Materials and Technologies Review
}

\author{
Yasmin M. Eid ${ }^{1}$, Mostafa A. El Ahwal ${ }^{2}$ Magda E. Ebied ${ }^{3}$, Rania H. Aly ${ }^{4}$
}

Received: 22 November 2020; Accepted: 18 January 2021

\begin{abstract}
Each organism has its unique and specific characteristics that have a great impact on the survival and adaptation processes. One of the most amazing and remarkable characteristics in some organisms such as crustaceans, cephalopods and some insects is the reversible color change property in their skin. This color change happens for various reasons such as thermoregulation, camouflage, and mating. It occurs due to the existence of the chromatophore, which is a special sort of pigment cells in their skin compositions. Chameleons are one of the most spectacular organisms that have this unique capability. This paper aims to demonstrate the property of chameleon's color change, its mechanism, and its applications in Architecture. In order to achieve this goal, different types of materials and glazing technologies that imitate this property and their applications in building's skin have been displayed. Besides, a schematic proposed framework inspired from the chameleon' skin has been introduced.
\end{abstract}

Keywords: Color Change, Chromatophores, Chameleon, Chromic, Smart Glazing.

\section{INTRODUCTION}

Each organism has its special characteristics that help to adapt and achieve its needs. One of the most unique characteristics is the ability of color change in some organism's skin. It has been found in many ectothermic species such as crustaceans, insects, and cephalopods, as seen in Figure 1. [1]
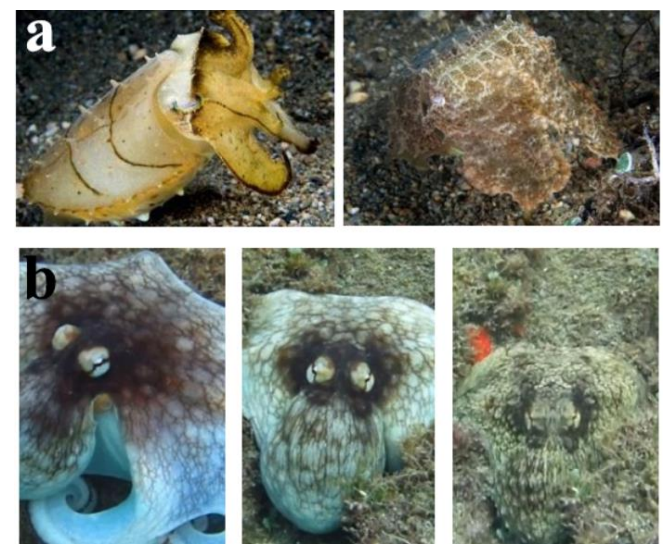

Figure 1: Organisms species that change color skin such as: (a) Cuttlefish [2] and (b) Octopus [3]

${ }^{I}$ Assistant Lecturer, Architecture and Urban Planning Department, Faculty of Engineering, Sinai University, North Sinai, Egypt, email: yasmen.mohamed@su.edu.eg, Corresponding Author

${ }^{2}$ Professor in Architecture and Urban Planning Department, Port-Said University, Port Said, Egypt, email: whitehouse.egypt@yahoo.com

3 Professor in Architecture and Urban Planning Department, Environmental Studies Institute, Ain Shams University, Cairo, Egypt, email:magda_ebeid@yahoo.com

${ }^{4}$ Lecturer in Architecture and Urban Planning Department, Port Saied University,Port Said, Egypt, email:dr.ranyaaly@gmail.com

DOI: $10.21608 /$ pserj.2021.50735.1072
The property of reversible color change occurs due to the existence of one or more types of Chromatophores in the skin's composition. Chromatophore is a Greek word; "chrōma" which means "dye" and "phoros" which means "bearing". It is a sort of pigment cells, which are generated in the neural crest during the genetic system development. It is responsible for generating the skin and eye colors and reflecting light as well. [4] [5] [6]

There are many types of Chromatophores. Bagnara. JT grouped them according to each type properties, color appearance, and the spectral of light absorbance, as seen in Table 1. Some types are pigment cells with specific color that transform between two colors according to light wavelength such as Xanthophores. The others are structural crystalized plates that reflect colors such as Iridophores. [5][6][7]

Table 1: Classification of Chromatophores' types according to properties, color appearance, and light absorbance [5] [6] [7]

\begin{tabular}{|c|c|c|c|}
\hline$H$ & Properties & $\begin{array}{c}\text { Color } \\
\text { Appearance }\end{array}$ & $\begin{array}{c}\text { Spectral of Light } \\
\text { Absorbance }\end{array}$ \\
\hline 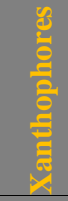 & Pigmentary & $\begin{array}{c}\text { Yellow } \\
\rightarrow \\
\text { Red }\end{array}$ & $\begin{array}{l}\text { Through the visible } \\
\text { light (range of } 440 \\
\text { to } 477 \mathrm{~nm} \text { ) }\end{array}$ \\
\hline 흘 & Pigmentary & $\begin{array}{c}\text { Yellow } \\
\rightarrow \\
\text { Red }\end{array}$ & $\begin{array}{l}\text { Through the visible } \\
\text { light (range of } 440 \\
\text { to } 477 \mathrm{~nm} \text { ) }\end{array}$ \\
\hline
\end{tabular}




\begin{tabular}{|c|c|c|c|}
\hline $\begin{array}{l}\frac{\pi}{0} \\
\frac{0}{2} \\
\frac{0}{0} \\
\frac{\pi}{0} \\
\Sigma\end{array}$ & Pigmentary & $\begin{array}{l}\text { Brown } \\
\stackrel{\rightarrow}{\text { Black }}\end{array}$ & $\begin{array}{l}\text { Through the visible } \\
\text { light (range of } 300 \\
\text { to } 700 \mathrm{~nm} \text { ) }\end{array}$ \\
\hline $\begin{array}{l}0 \\
\frac{0}{0} \\
\frac{0}{2} \\
\frac{0}{0} \\
\frac{0}{\exists}\end{array}$ & Structural & $\begin{array}{c}\text { Reflective } \\
\text { Iridescent } \\
/ \\
\text { silvery }\end{array}$ & $\begin{array}{l}\text { Through } 350-400 \\
\mathrm{~nm} \text { and } 500-600 \\
\mathrm{~nm}\end{array}$ \\
\hline $\begin{array}{l}0 \\
0 \\
0 \\
0 \\
0 \\
0 \\
0 \\
0 \\
\end{array}$ & Structural & $\begin{array}{c}\text { Reflective } \\
\text { White }\end{array}$ & $\begin{array}{l}\text { Through } 300-700 \\
\text { nm especially in the } \\
\text { UV Range }\end{array}$ \\
\hline
\end{tabular}

Color changing differs from organism to other according to the chromatophores' types, which exists in the skin' layers. However, the vital question is how do chromatophores work? Many researchers conducted that the color change happens due to two main reasons as follows: [5] [8] [9]

- The first reason is the chromatophores types that exist in the skin composition. As each organism has more than one type of chromatophores to shift between colors, as seen in Figure 2 a.

Reflectance depends on
thickness, spacing and orientation

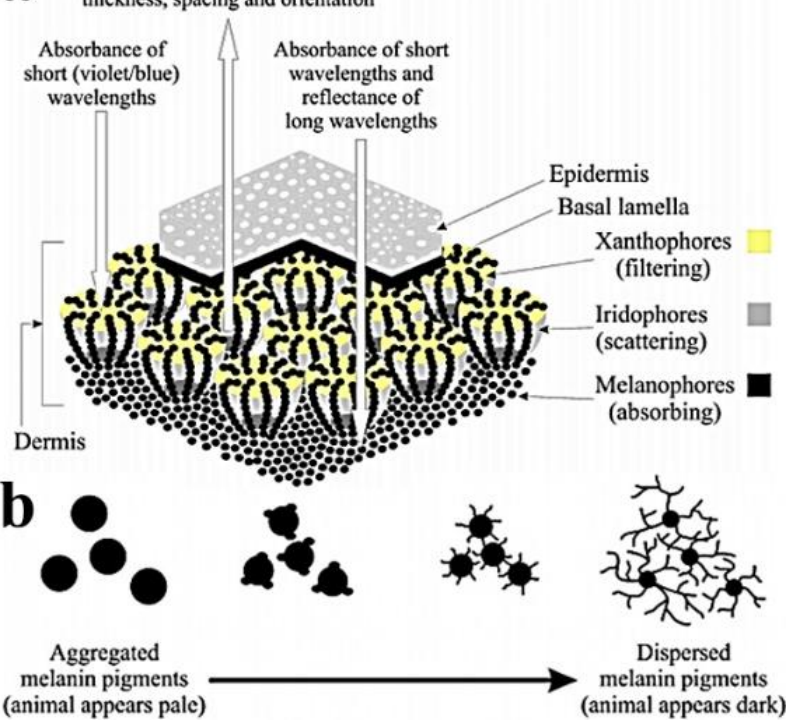

Figure 2: the schematic design shows the structure and function of chromatophores types in the skin: (a) different types of chromatophores, which exist in skin layers and (b)

how melanophores are aggregated to let the organism appears dark or spreaded to let the organism appears pale dye [5]

- The second reason is the mechanism of how the chromatophores work. There are two mechanisms. The first one is by chromatophores structure, shape, and form in skin structure, as seen in Figure 3. The second mechanism is the muscles control that disperse, aggregates, or expands the chromatophores, as seen in Figures 2 b \& 4 .
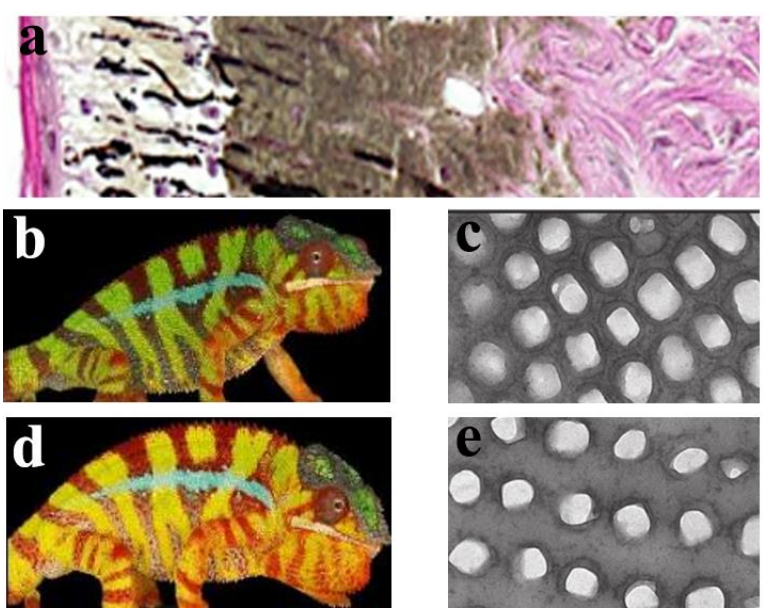

Figure 3: Chromatophores in Chameleon's skin composition: (a) skin layers from the left; the dermis, superficial iridophores, deep iridophores, and melanophores, (b) while the chameleon is relaxed, (c) iridophores expand and seem converging, (d) while the chameleon is excited (e) iridophores are shrink and seem divergent [8]
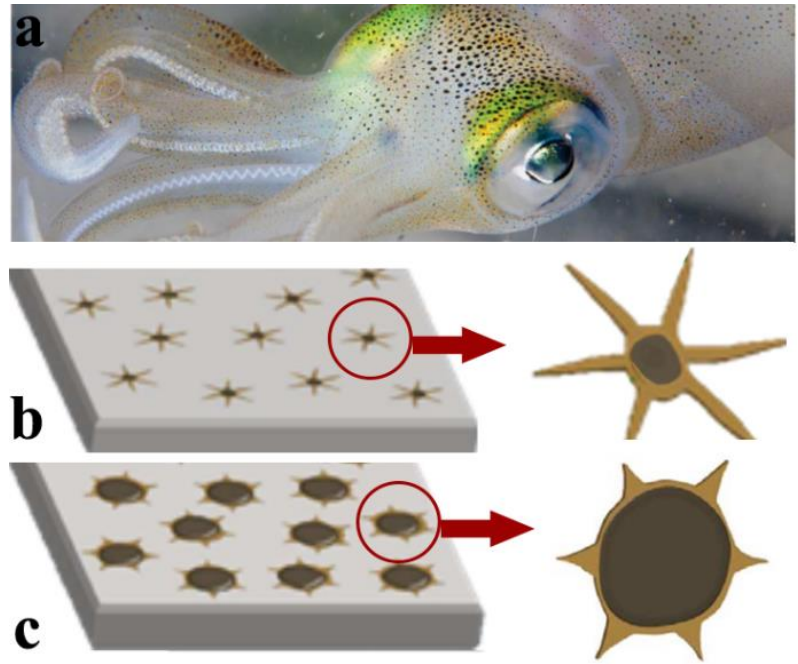

Figure 4: Elastic chromatophores controlled by radial muscles in the Squid: (a) the chromatophores appearance in the skin, (b) while the radial muscules shrink the chromatophore cell, and (c) while the radial muscles expand the chromatophore cell [9]

\section{METHODOLOGY}

This paper illustrates the property of reversible color change of the chameleon' skin as one of the most amazing organisms. Then, many adaptive and smart technologies that imitated this property in architecture have been reviewed. Along with that, some applications in architecture specifically in the building skin have been introduced. Finally, a practical framework inspired by chameleon' skin has been proposed. See Figure 5. 


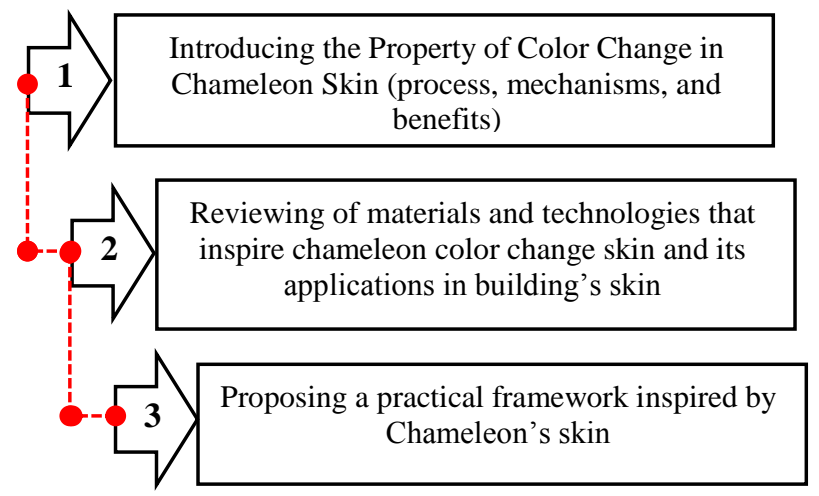

Figure 5: Research methodology is divided into three stages, drawn by the researcher

\section{CHAMELEON'S ADAPTIVE SKIN}

Chameleons are one of the vertebrate's species. It is an ectothermic organism that regulates the body temperature with the surrounding environment. [10]

Chameleon is one of the most incredible organism that can change its skin's color for many reasons such as camouflage or mating. However, the most interesting output of this change is the body's thermal regulation. It can reduce the heat gain in the extreme high temperature by about $45 \%$ through its skin only. [8][1]

It is obvious from Figure 3 that chameleon's skin consists of four layers. In addition to epidermis, two types of chromatophores exist in the skin. The first type is two layers of Iridophores and the second type is the melanophores. The mechanism that the chameleon follows for color change is the transformation of the superficial Iridophores structure, form, and shape, as seen in Figure 6. [8]

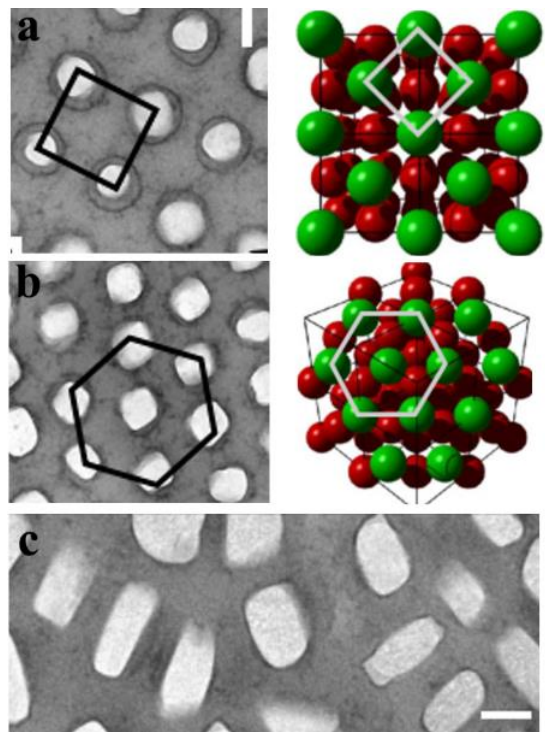

Figure 6: Two shapes and layers of iridophores in chameleon skin: (a) 2D and (b) 3D structural and form transformations of the superficail iridophores layer when the chameleon is excited and (c) unorganized and different shapes of the deep iridophores layer [8]

\section{ADAPTIVE TECHNOLOGIES INSPIRED BY CHAMELEON'S SKIN}

Many scientists inspired and practiced the property of color change such as the chameleon's skin in many different fields. For example, they applied the function of color change for workers' uniform to alarm them in the dangerous zones and save their lives, as seen in Figure 7. [11]
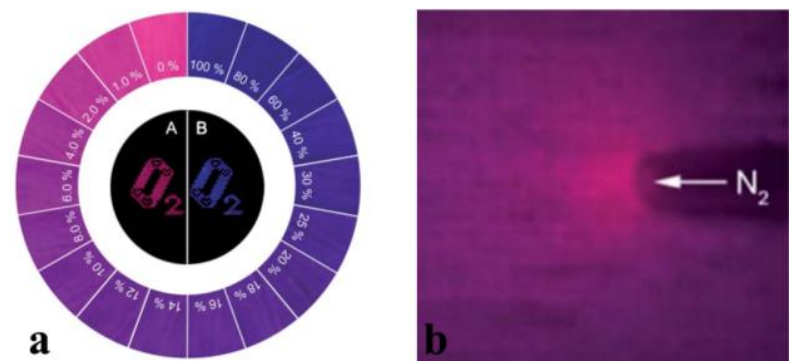

Figure 7: Chameleon cloth as an application of the color change property: (a) cloths at different concentrations of

Oxygen and (b) the color changes when it exposes to Nitrogen in the air flow [11]

Another livelier application is the e-skin device that is applied in the prosthesis' industry. The e-skin is a stretchable device that changes color to notify the user when the prosthesis exposes to pressure, as seen in Figure 8. [1]

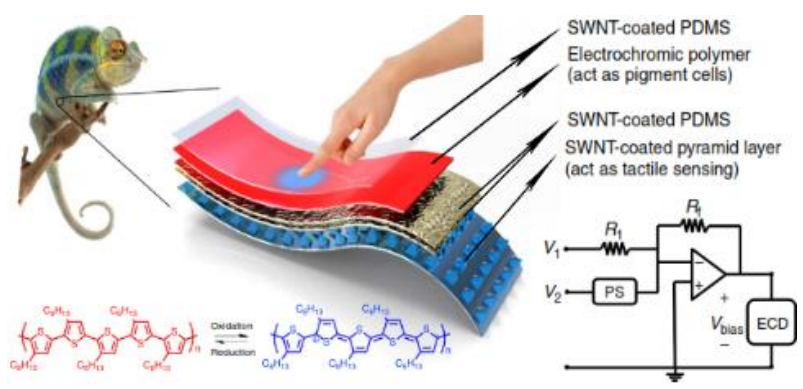

Figure 8: E-Skin proposal is inspired from chameleon skin and consists of four compacted layers: electrochromic polymer stacked between double layers of SWNT coated and SWNT coated pyramid layer [1]

\section{MATERIALS AND TECHNOLOGIES INSPIRED BY CHAMELEON'S SKIN IN ARCHITECTURE}

\subsection{Chromic Materials}

Chromic materials, also termed as chromogenic or chameleonic, are smart materials that exchange color due to a different external stimulus such as light or temperature conditions or by an induced stimulus such as chemicals, electrical, or mechanical. There are many types of chromic materials. Some of them are applied and commercialized successfully but the others are still at the developmental stage. See Figure 9. [12] [13] [14] 


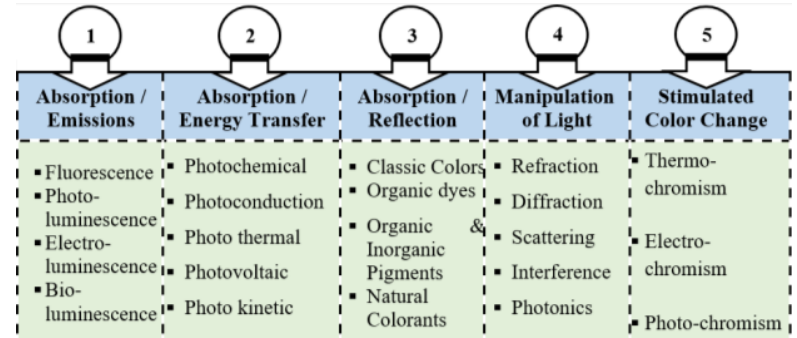

Figure 9: The five groups of chromic materials [14]

\subsubsection{Stimulated Color Change Materials}

Stimulated color change materials are one of the most vital smart chromic materials generally and in the architecture particularly. They change color from a color to another, from colored to colorless, or from light to dark due to the exposure to an external stimulus that changes electrons equilibrium in a material. This process is called "chromism". The chromism process may keep the material's chemical bonds without any change or can make some changes in the material's optical properties such as reflectivity, absorption or transmission. When the stimulus stops, the material electrons return to its original state and regain the initial color or transparency properties. [12][13][14][15][16]

Color change chromogenic materials are represented in different types of switching smart glazing. They are classified according to the stimulus that causes the changing of color. However, they could be also classified as shown in Figure 10: [15] [16]

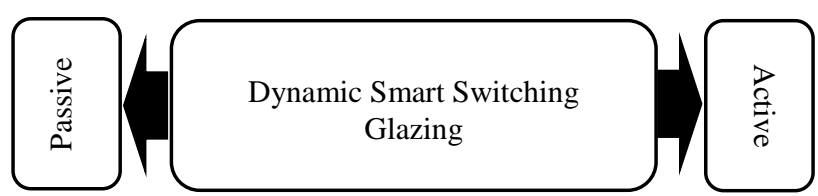

Figure 10: The dynamic smart glazing that applied chromogenic materials is divided into passive glazing and active glazing [15] [16]

\section{A. Thermochromic Glazing (Passive Material)}

Passive materials are smart organic and inorganic materials that can change their properties due to external stimulus such as light, temperature, solar radiation, or pressure. Thermochromic glazing system is considered as a reversible smart type of the passive materials. Thermochromic material could be coating or film manufactured from solid chemical compounds such as Vanadium dioxide, which works as semiconductor layer and stacked between double glazed panes, as seen in Figure 11. It can change its optical phase due to chemical reactions at a specific "transition" temperature. When the temperature is low, the material becomes transparent, and when the temperature is higher, the system becomes opaque. See Figure 12. [15] [17]

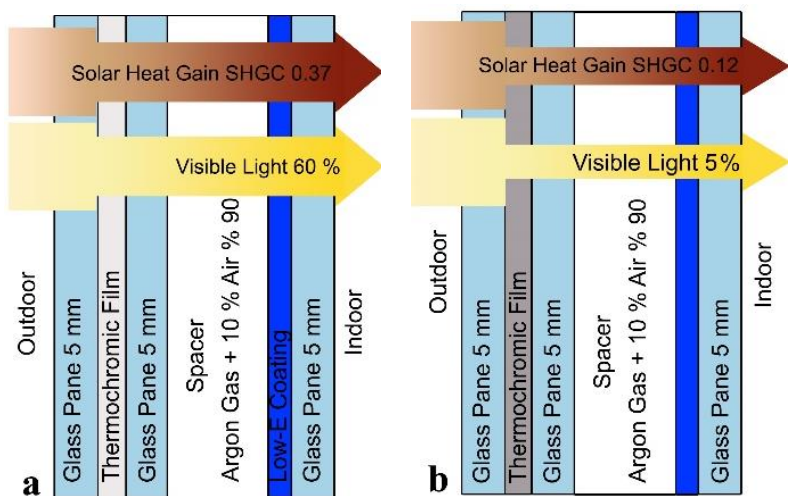

Figure 11: Thermochromic layer stacked between double panes: (a) while glazing is at low temperature, it becomes transparent and (b) while it is at high temperature, it becomes opaque [15]

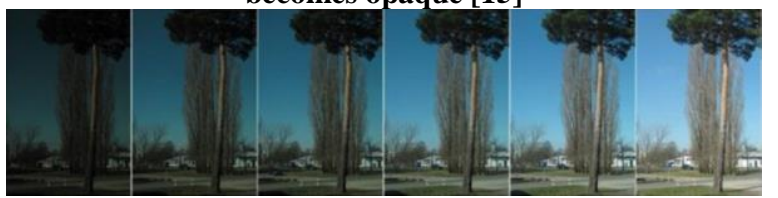

Figure 12: Thermochromic glazing system while switching color during different hours [17]

Thermochromic glazing system has been applied in several building such as the civil engineering building's skin in Cambridge university campus in UK in order to maintain the thermal comfort for users, as seen in Figure 13. [18][19][20] It has been also applied in the National Disability Insurance Agency [NDIA] Headquarter, Geelong in Australia, 2016, as seen in Figure 14. [21]

Although this system has been applied in many countries, it doesn't spread as expected in the commercial market due to its high cost, unpleasant color and low visible daylight transmission, in addition, it works effectively only in hot climates. [15] [17]

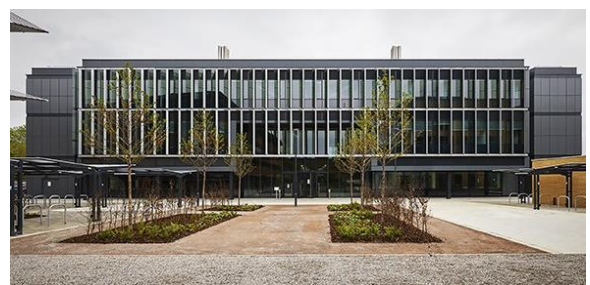

Figure 13: Applying thermochromic glazing in the Civil engineering facades, Cambridge University, United Kingdom, to maintain thermal comfort [18]

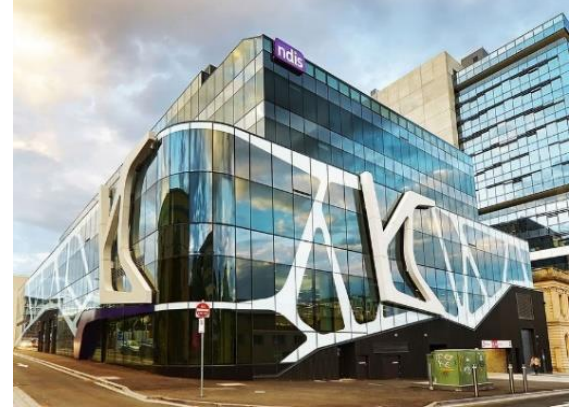

Figure 14: Thermochromic glazing facades of NDIA headquarter, Geelong in Australia [20] 


\section{B. Electrochromic Glazing (Active Material)}

Active material is a type of smart materials. It responds also to the changes in the external stimulus such as the passive material but it needs an electrical field to switch their optical properties. It also can be controlled by a computerized building management system or by smartphones as a remote control. [15]

The electrochromic glazing is considered the most popular and useful application of the active chromic materials in the commercial market. It is presented as a cathode thin film such as Tungsten trioxide or as an anode film such as Iridium oxide. It consists of two ions layers; a conductor layer and storage layer stacked between sandwiched glass panels in transparent conductive oxide, as seen in Figure 15. [22]

When applying an electrical voltage, ions are extracted from the storage layer and pass to the electrochromic layer, which thereby change optical properties. When it is turned off, the ions return to the storage layer and make the electrochromic layer transparent again, as seen in Figures 16. [15]
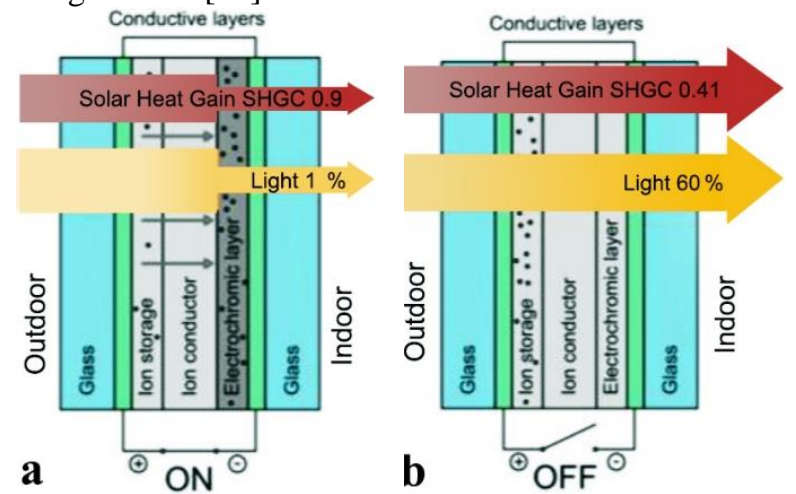

Figure 15: The visible light and solar heat gains ratio in the electrochromic glazing system (a) while opaque mode and (b) while transparent mode [15]
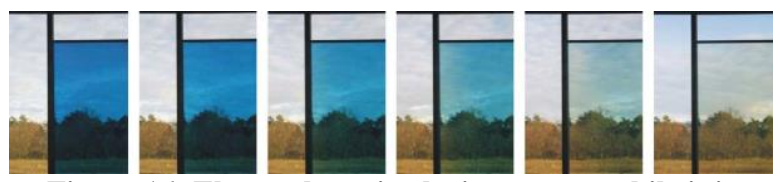

Figure 16: Electrochromic glazing system while it is switching during different hours [23]

The electrochromic glazing also has been applied in several buildings such as the Festo Automation Center building, Esslingen in Germany to reduce light and thermal transmittance, whilst maintaining transparency, as seen in Figure 17. [24] The Yard, Chicago Shakespeare in USA is another example for applying electrochromic glazing on the south façade only to provide the thermal comfort and outdoor vision for the users, as seen in Figure 18. [25]
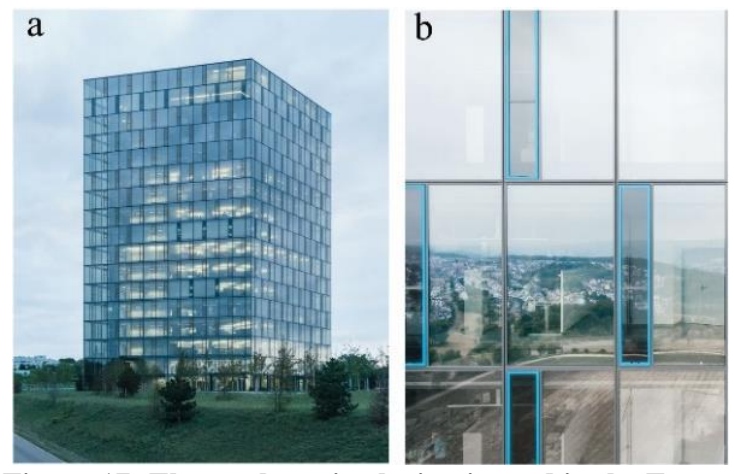

Figure 17: Electrochromic glazing is used in the Festo

Automation Center facades, Esslingen, Germany (a) an external view of the whole building and (b) A focus on some facades' units [24]
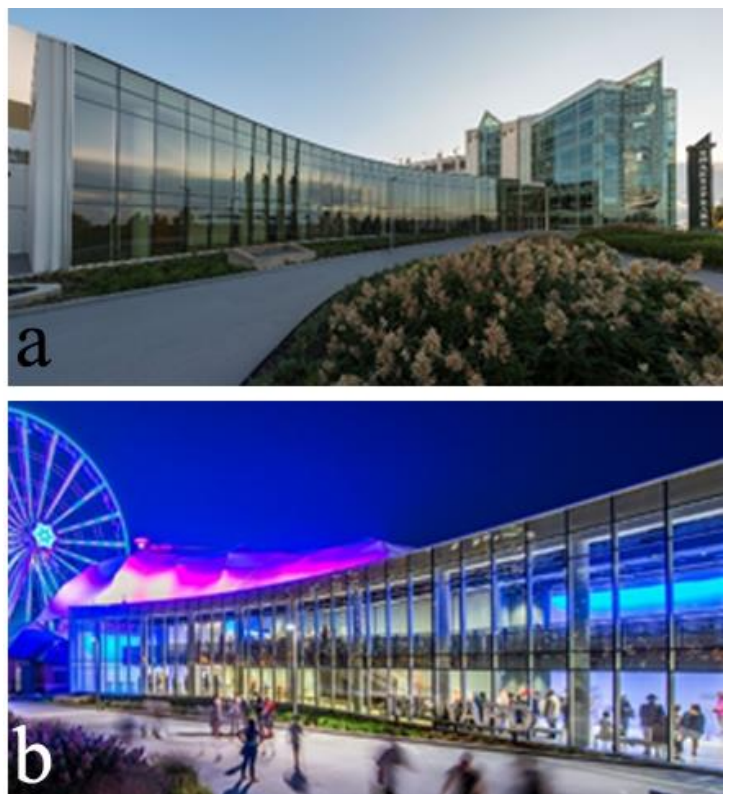

Figure 18: Electrochromic glazing is used in the south façade of the Yard, Chicago Shakespeare in USA (a) the facade is opaque at daytime to control heat gain and (b) the glazing façade is transparent at night [26]

\subsection{Adaptive Fritted System}

The adaptive fritted system is a functional unique technology that acts as the skin of the Namaqua Chameleon. The system was innovated to provide the architects with a new tool that can increase the transparency of the glazing facades while shaded. It is also used for controlling the solar heat gain.

Adaptive fritted system is a multi-layer of a fixed pattern of circled acrylic stacked together in orthogonal axes. These axes motions are controlled by an electromagnetic motor that spread the circles as fan wings to cover the interspaces between them. The glazing panel modulates between opaque and transparent states through the fritted system converging or diverging respectively, as seen in Figures $19 \& 20$. 
The Adaptive Fritted system was developed in 2009 by Hoberman Associates for the Harvard Graduate School of Design building, in Cambridge USA, as an initiative adaptive building shading technology. It has been used for internal partitions to provide privacy for the users, as seen in Figure 21. [27] [28] [29]

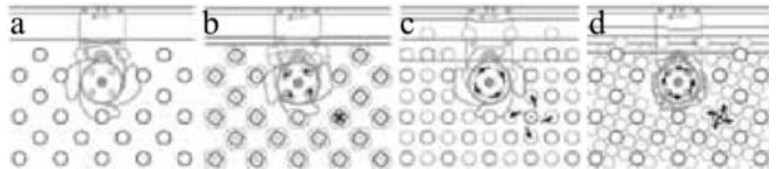

Figure 19: Adjustment the fritted density by a motorized operational scheme: (a) while it is tranparent, $(b, c)$ translucent, and (d) opaque[28]
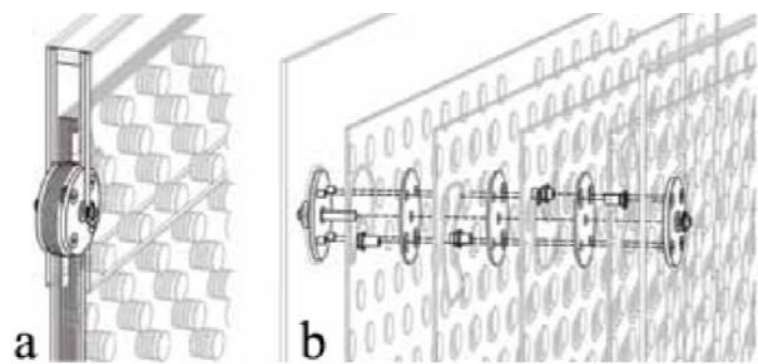

Figure 20: Adaptive fritted panel section illustrates (a) stacked up multi panels and (b) rotational axial mechanism in the stacked Panel [28]

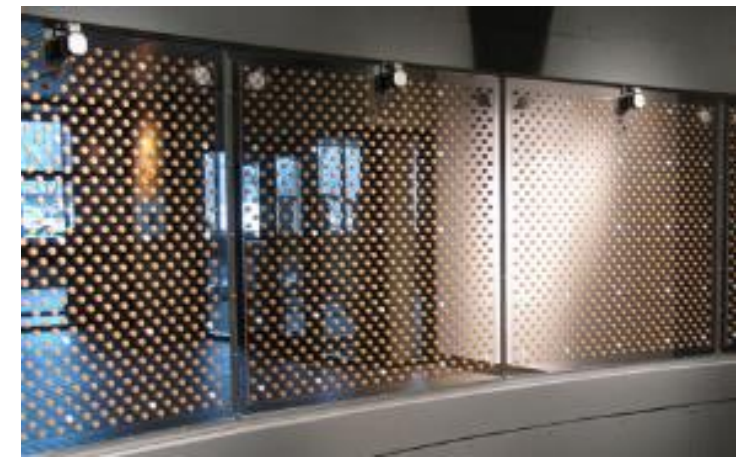

Figure 21: Internal partitions of adaptive fritted panels, Harvard GSD building [28]

The concept of the adaptive fritted system also has been applied in other buildings; for example the Interactive cope headquarter building designed by Frank Gehry. He installed various statically fritting glazing on the facades in order to control the solar heat gain while transmit the natural daylight, as seen in Figures $22 \& 23$. [28] [30]
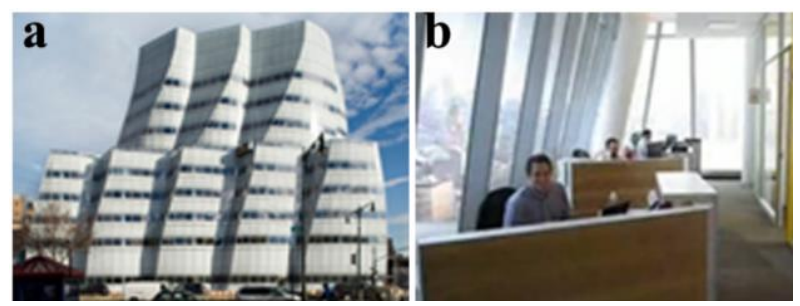

Figure 22: The Interactive cope headquarter office building: (a) outdoor [29] and (b) internal spaces [31]
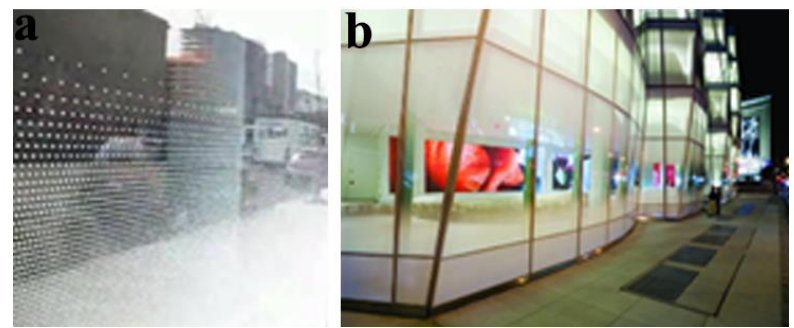

Figure 23: Transparent and opaque parts in the Interactive cope headquarter facades (a) at day [31] and (b) at night

[30]

\subsection{Decorative Panels}

A decorative board is inspired by chameleons for internal and external facades cladding, external ceiling, and filling boards. It is designed to show unusual appearance and changing color depending on the angle of view and sunlight rays, such as Chameleons, as seen in Figures 24.

This board is a manufactured panel produced by compressing mineral wool boards of volcanic rocks, then, treated with four layers of water polymer emulsion paint on one side, and finished with a unique crystal layer, which causes color changing. This board may be treated with a fifth layer of self-cleaning or anti-gravity material.

Decorative panels have been applied in many buildings, such as Think Tank Innovation Center in Lincoln University in UK and Les Trèfles primary school in Anderlecht in Belgium, Europe, as seen in Figures 25 \& 26. [32] [33]

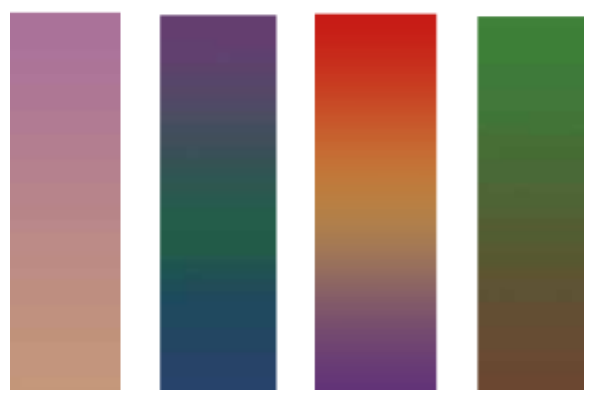

Figure 24: Different Colors of decorative panels [33]

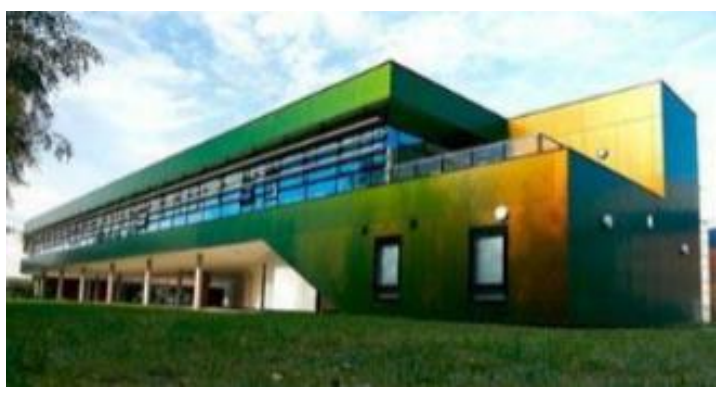

Figure 25: The chameleon decorative panels at Think Tank Innovation Center facades, Lincoln University, United Kingdom [34] 


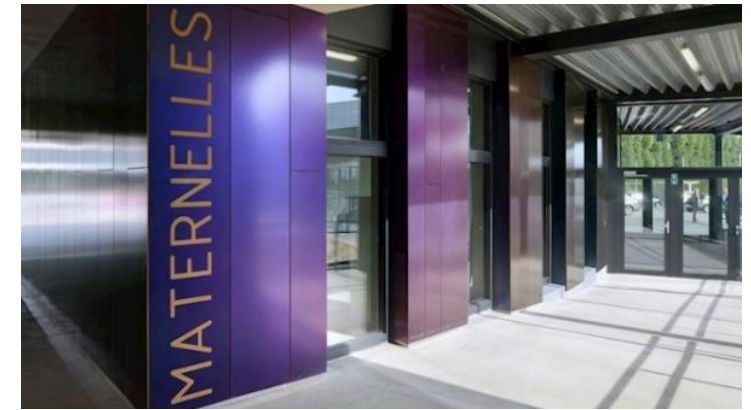

Figure 26: The chameleon decorative panels at Les Trèfles primary school in Anderlecht, Belgium, Europe [35]

\section{PRACTICAL FRAMEWORK}

Based on the previous review, the adaptive technology inspired by chameleon skin could be summarized as follows:

- Materials with specific properties; these materials are able to absorb and reflect heat.

- Transformation Mechanism; An axial motion of those materials.

Consequently, the researcher proposed a glazing section inspired by the chameleon' skin. This hypothesized proposal consists of four layers; clear layer, two reflective layers, and an absorptive layer, as seen in Figures 27. The clear and absorptive layers are fixed. The two reflective layers can rotate vertically around a vertical axis. Electric and mechanical components will support the motion mechanism of these layers. In addition, temperature sensors should be installed to control automatically when the system opens and closes.

This hypothesized proposal could be modified according to many factors such as, the building type, the location, the climate, and the energy efficiency requirements of different building codes.

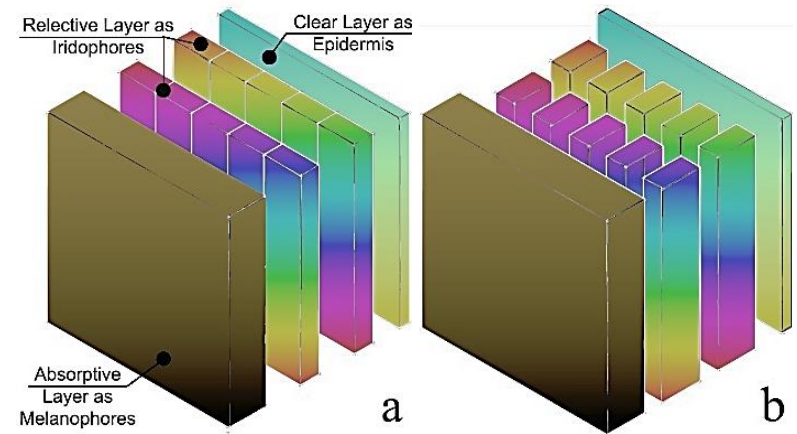

Figure 27: The proposed wall section consists of four layers; the first is clear, the second and third are reflective layers, and the fourth is absorptive layer (a) while it is closing to reflect heat and (b) while it is opening to gain heat

\section{ANALYSIS AND DISCUSSION}

Chameleon is one of organisms that changes its skin's color reversibly. It changes its color not only for mating and camouflage but also for its body's thermoregulation.
This change is due to the existence of two types of chromatophores in its skin' composition; double layers of Iridophores and Melanophores. The mechanism that chameleon applies is by transforming Iridophores' structure, shape, and form. This transformation increases and decreases the distance between the superficial Iridophores plates to transmit or prevent sun heat respectively. Due to the transformation mechanism and crystalized characteristics of Iridophores, the color change property is resulted from sunlight reflections in different wavelengths.

The chameleon's color change capability has been inspired in the development of adaptive applications in both medical and industrial fields. In addition, many adaptive technologies have been developed in Architecture.

Some inspired materials and technologies in architecture are mainly depending on the visual concept of the color change property of chameleon, such as the decorative boards. Other technologies inspired more than the visual concept. They inspired the thermoregulation concept, Such as the chromic materials that can change their own properties and physical characteristics in order to control the amount of heat gain and maintain the users' thermal comfort.

Both of passive and active smart materials are changing color through transforming their optical properties. The optical properties change in the thermochromic glazing through the conversion from transparent to opaque mode, while in the electrochromic glazing through the conversion from light to dark mode. The thermochromic transformation mechanism is resulted from chemical reactions, while the electrochromic transformation mechanism is resulted from ions' movement from a layer to another layer.

Thermochromic and electrochromic glazing have been developed to show a remarkable reduction in energy consumption for both heating and cooling demand, through controlling heat transmittance and visible light while transformation between two specific colored modes. However, they have a negative impact on daylight transmission into the space as they change their appearance from light to dark, which could also affect the visual comfort in working space, in addition to other negative impacts such as unpleasant and constant appearance.

Another application that inspires the functional concept is the Fritted glazing. This glazing system has been installed in the external facades as a shading device to control heat gain and provide the users with natural daylight. It could be also used as an internal partition to achieve privacy between different working areas. The transformation mechanism from transparent to opaque mode occurs through an electromagnetic motor that converges or diverges the internal particles, respectively. 


\section{CONCLUSION}

Chameleon is one of the organisms that can change their skin's color due to the existence of chromatophores' types in their skin's compositions. This capability is considered one of chameleon's adaptation techniques for thermoregulation process in extreme heat, in addition to other reasons such as camouflage and mating.

This unique reversible color change of chameleon's skin inspired many researchers in several fields that serve human.

Architecture is one of the practical fields that represented many adaptive technologies inspired by these capabilities. Although few applications inspired the color change as a visual concept, many adaptive materials inspired the color change as both the functional concept of thermoregulation and the visual concept as well such as the Thermochromic glazing, the Electrochromic glazing, and the Fritted glazing.

Although thermochromic, electrochromic, and fritted glazing can all control heat transmittance as Chameleon's skin, thermochromic glazing is considered the more closer application to the chameleon in the transformation mechanism than electrochromic and fritted glazing.

In addition, these previous applications are representing the color change concept in just two constant color modes, unlike chameleon.

Finally, a hypothesized practical framework has been proposed. This proposed framework would be tested in the future to identify the following:

- The convenient materials that could achieve the target.

- The best integrated technology that could achieve the highest energy performance.

\section{CREDIT AUTHORSHIP CONTRIBUTION STATEMENT:}

Yasmin M. Eid: Generating the idea, Collecting data, Methodology \& Original draft preparation, Mostafa M. Abd Elhafeez: Reviewing \& Supervision, Magda E. Ebied: Reviewing \& Supervision, Rania H. Aly: Validation, Editing, Reviewing \& Supervision.

\section{DECLARATION OF COMPETING INTEREST:}

The authors declare that they have no known competing financial interests or personal relationships that could have appeared to influence the work reported in this paper.

\section{References}

[1] H. Chou, A. Nguyen, A. Chortos, C. W.F.To.J.LU, J. Mei, T. Kurosawa, W. Bae, J. B-H. Tok and Z. Bao, "A Chameleon-Inspired Stretchable Electronic Skin with Interactive Colour Changing Controlled
By Tactile Sensing," Nature Communications, pp. 110, 2015.

[2] D. Stuart-fox, "How Do Chameleon and Other Creatures Change Color," 2013. [Online]. Available: hhttps://phys.org/news/2013-05-chameleonscreatures-coloures.html. [Accessed 18 November 2018].

[3] J. O'CALLAGHAN, "Spot the octopus! Amazing moment marine creature camouflages itself against a reef is captured on video," Daily Mail, 4 February $2015 . \quad$ [Online]. Available: https://www.dailymail.co.uk/sciencetech/article2939261/Spot-octopus-Amazing-moment-marinecreature-camouflages-against-reef-capturedvideo.html. [Accessed 20 December 2018].

[4] S. Nilsson, Autonomic Nerve Function in the Vertebrates, vol. 13, Berlin: Springer, 1983, pp. 198201.

[5] J. Kelly and W. Davies, "The Biological Mechanisms and Behavioral Functions of Opsin-Based Light Detection by the Skin," Frontiers in Ecology and Evolution, vol. 4, pp. 1-13, 2016.

[6] A. Lapedriza, K. Petratou and R. Kelsh, "Neural Crest Cells and Pigmentation," in Neural Crest Cells: Evolution, Development and Disease, Academic Press, 2014, pp. 287-311.

[7] J. T. Bagnara, "Cytology and cytophysiology of nonmelanophre pigment cells," International Review of Cytology, pp. 173-205, 1966.

[8] J. Teyssier, S. Saenko, D. Marel and M. Milinkovitch, "Photonic Crystals Cause Active Colour Change in Chameleon," Nature Communications, pp. 1-7, 2015.

[9] Q. Wang, G. Gossweiler, S. Craig and X. Zhao, "Cephalopod-inspired Design of Electro-MechanoChemically Responsive Elastomers for On-Demand fluorescent Patterning," Nature Commuincation, pp. 1-9, 2014.

[10] "Temperature Regulation Strategies," Khan Academy , [Online]. Available: https://www.khanacademy.org/science/biology/princi ples-of-physiology/metabolism-andthermoregulation/a/animal-temperature-regulationstrategies. [Accessed 2 Februrary 2019].

[11] X.-d. Wang, T.-y. Zhou, X.-h. Song, Y. Jiang, C. Yang and X. Chen, "Chameleon clothes for quantitative oxygen imaging," Journal of Materials Chemistry, pp. 17651-17653, 2011.

[12] M. Vik, , A. P. Periyasamy, and M. Viko, Chromic Materials: Fundamentals, Measurements, and Applications, Apple Academic Press, Taylor \& Francis, 2019.

[13] M. Ferrara and M. Bengisu, "Intelligent design with chromogenic materials," Journal of the International Colour Association, p. 54:66, 2014.

[14]P. Bamfield and M. Hutchings, Chromic Phenomena: The Technological Applications of 
Colour Chemistry, United Kingdom: Royal Society of Chemistry, 2018.

[15] M. Casini, "Smart windows for energy efficiency of buildings," in Advances In Civil, Structural and Environmental Engineering, USA, 2015.

[16]M. S. Abeer , "Smart Materials Innovative Technologies in Architecture; Towards," in Alternative and Renewable Energy Quest, Spain, 2017.

[17] M. Kamalisarvestani, R. Saidur and S. Mekhilef, "Performance, Materials and Coating Technologies of Thermochromic Thin Films on Smart Windows," Renewable and Sustainable Energy Reviews, pp. 813-826, 2013.

[18] "Department of Engineering," 24 September 2019. [Online]. Available: http://www.eng.cam.ac.uk/news/opening-new-civilengineering-building-make-significant-contributionuk-infrastructure-research. [Accessed 20 November 2020].

[19] "Cambridge University chooses Suntuitive Dynamic Glass," 11 November 2019. [Online]. Available: https://www.glassonline.com/cambridge-universitychooses-suntuitive-dynamic-glass/. [Accessed 20 November 2020].

[20] "Dynamic Glass Projects," [Online]. Available: https://suntuitiveglass.com/dynamic-glassprojects/\#. [Accessed 21 November 2020].

[21] "Carlton Project, National Disability Insurance Agency Headquarters," [Online]. Available: https://www.kane.com.au/project/ndia-the-carltonproject1. [Accessed 18 November 2020].

[22] J. MOHELNIKOVA, "Nanocoatings for architectural glass," in Nanocoatings and Ultra-Thin Films: Technologies and Applications, Czech Republic, Woodhead Publishing Limited, 2011, pp. 182-202.

[23]R. Baetens, B. P. Jelle and A. Gustavsen, "Properties, requirements and possibilities of smart windows for dynamic daylight and solar energy control in buildings: A state-of-the-art review," Solar Energy Materials \& Solar Cells, pp. 87-105, 01 October 2009.

[24] "Festo "Automation Center"," Schlaich bergermann partner , 2015. [Online]. Available: https://www.sbp.de/en/project/festoautomationcenter/. [Accessed 18 November 2020].

[25] "Yard Chicago Shakespeare USA," Saint Gobain, [Online].

Available: https://www.sageglass.com/en/case-studies/yardchicago-shakespeare-usa. [Accessed 20 November 2020].

[26] "The Yard At Chicago Shakespeare," Chicago Architecture Building, [Online]. Available: https://www.architecture.org/learn/resources/buildin gs-of-chicago/building/the-yard-at-chicagoshakespeare/. [Accessed 20 November 2020].
[27]I. Hoberman Associates, "Statement of Qualifications," 2011. [Online]. Available: http://www.hoberman.com/about.html. [Accessed 25 August 2019].

[28]Z. Drozdowski and s. Gupta, "Adaptive Fritting as Case Exploration for Adaptivity in Architecture," in Building a Better Tomorrow , Chicago, Illinois, 2009. BIBLIOGRAPHY \m Yar \l 1033

[29] "Turner Construction," [Online]. Available: https://www.turnerconstruction.com/experience/proj ect/20/the-iac-building. [Accessed 25 August 2019].

[30] S. MATTERN, "Edge Blending: Light, Crystalline Fluidity, and the Materiality of New Media at Gehry's IAC Headquarters," in Media Houses: Architecture, Media and the Production of Centrality, New York, Words in Space, 2010, pp. 137-161.

[31] J. Feldman, Director, A Look Inside the New IAC Headquarters. [Film]. Viemo, 2007. [Accessed 8 August 2019].

[32]RockWool Company, "Product Data Sheet Rock Panel ${ }^{\circledR}$ chameleon: Durable - Xtreme - FS-Xtra," 2014. [Online]. Available: https://m.encon.co.uk/sites/default/files/products/do wnloads/productsheet_rockpanel_chameleon.pdf. [Accessed 15 March 2019].

[33]Rock Panel Group, "Façade solutions: product range," 2017. [Online]. Available: https://www.rockpanel.es/siteassets/documentation/u k/brochures/rockpanel_assortment_brochure.pdf. [Accessed 15 March 2019].

[34] "Rockpanel_chameleon," Holzbau Wassmer De, [Online]. Available: https://www.holzbauwassmer.de/marke_hersteller_produkte/rockpanel/roc kpanel_chameleon. [Accessed 20 November 2020].

[35] "Sustainable School turns a new Leaf," Rock Panel, [Online]. Available: https://www.rockpanel.co.uk/inspiration/lestrefles/. [Accessed 20 November 2020]. 